\title{
Bone mineral density, body composition and metabolic profiles in adult women with complete androgen insensitivity syndrome and removed gonads using oral or transdermal estrogens
}

\section{Giulia Gava', Ilaria Mancini', Isabella Orsili', Silvano Bertelloni' ${ }^{2}$, Stefania Alvisi' Renato Seracchioli' ${ }^{1}$ and Maria Cristina Meriggiola' ${ }^{1}$}

${ }^{1}$ Gynecology and Physiopathology of Human Reproduction, S. Orsola-Malpighi Hospital, Department of Medical and Surgical Sciences (DIMEC), University of Bologna, Bologna, Italy and ${ }^{2}$ Pediatric Division, Department of Obstetrics, Gynecology and Pediatrics, Azienda Ospedaliero-Universitaria Pisana, Pisa, Italy
Correspondence should be addressed to G Gava

Email

giulia.gava2@unibo.it

\begin{abstract}
Objectives: To assess bone health in adult women with complete androgen insensitivity syndrome (CAIS) and removed gonads compared with age-matched healthy controls. To evaluate the effects of transdermal oestradiol $2 \mathrm{mg}$ or oral estradiol valerate $2 \mathrm{mg}$ on bone, biochemical and clinical characteristics.

Design: Cohort study.

Methods: Bone, body composition and anthropometric parameters were assessed in 32 adult CAIS and 32 healthy controls. In 28 cases, CAIS evaluations of metabolic, bone and body composition were performed also after a maximum of 6 years of therapy.

Results: Lumbar, femoral and total body bone mineral density (BMD) were significantly lower in those with CAIS when compared with controls. The prevalence of vertebral osteoporosis and osteopenia was significantly higher in the CAIS group $(P=0.038, \mathrm{OR}=9.67,95 \% \mathrm{Cl}: 1.13-82.83$ and $P=0.012, \mathrm{OR}=3.85,95 \% \mathrm{Cl}: 1.34-11.16$, respectively). Prevalence of femoral osteopenia was significantly higher in the CAIS group $(P=0.0012$, OR $=7.93,95 \% \mathrm{Cl}: 2.26-27.9)$. During follow-up, lumbar BMD significantly increased suggesting a significant effect of treatment on BMD $(P=0.0016)$, while femoral and total body BMD did not show any significant change. Total body BMD values were positively associated to the duration and route of oestrogen administration and to serum estradiol levels. Transdermal administration of estrogens was associated with better total body BMD in comparison to oral administration.

Conclusions: Our results reinforce the importance of adequate hormonal treatment for women living with CAIS, suggesting a better effect from the transdermal route over the oral route.
\end{abstract}

\section{Introduction}

\section{Background}

Complete androgen insensitivity syndrome (CAIS) is the most common 46,XY disorder of sex development (DSD) with an estimated incidence of 1-5 per 100,000 births (1).
This syndrome is characterised by complete androgen resistance in androgen-dependent tissues caused by mutations in the androgen receptor (AR). Bone health is a major concern in women with CAIS because of the known importance of estrogens and androgens on the

Published by Bioscientifica Ltd. 
growth and maintenance of the skeleton. In CAIS women, the combined skeletal resistance to androgen action and oestrogen deficiency can result in decreased bone mineral density (BMD). In this regard, optimal timing of gonadectomy is still debated $(2,3,4,5)$. Both adolescent and adult CAIS with removed gonads showed reduced BMD mainly in the lumbar region $(6,7,8,9,10,11)$. Low BMD has been also related to inadequate hormone replacement therapy (HRT) after gonadectomy $(8,12)$ but whether appropriate HT is sufficient to maintain bone health is unclear. Adult CAIS appropriately treated with HT showed better lumbar and femoral BMD values (7, 9); however, these studies were quite heterogeneous with various formulations and doses of HT and only included a small number of cases or reports of single individuals.

\section{Objectives}

The primary aim of our study was to assess bone health in adult women with CAIS and removed gonads at the time of their first visit to our gynaecological centre compared with age-matched healthy controls. The secondary aims of our study were to evaluate the effects of two types of oestrogen therapy (transdermal estradiol gel $2 \mathrm{mg}$ or oral estradiol valerate $2 \mathrm{mg}$ ) on bone, biochemical and clinical characteristics of CAIS patients.

\section{Subjects and methods}

\section{Study design and population}

In this cohort study we evaluated 32 adult patients with CAIS and removed gonads. The female control group included 32 healthy age-matched women. Women were selected from patients who attended the Gynecology and the Physiopathology of Human Reproduction Unit at S. Orsola University Hospital in Bologna.

All CAIS patients presented 46, XY karyotype with confirmed AR mutation and external female genitalia. Inclusion criteria were CAIS diagnosis with complete genetic work-up and previous bilateral gonadectomy. Exclusion criteria were previous testosterone intake and intact gonads. The control group was age matched (for each CAIS there was a healthy control of the same age). With the control group, inclusion criteria were regular menstrual cycles and normal ovaries at ultrasound, while exclusion criteria included diseases or current/previous drugs causing bone impairment and current or previous hormonal treatments.
All participants were in good physical health at the time of enrolment and were asked about previous illnesses and medication use, current and past smoking habits, and physical activities.

The following data were recorded for CAIS patients: age at gonadectomy, age at starting estrogens, type and dose of estrogens (oral vs transdermal).

We compared spine, femoral and total body BMD and body composition in women with and without CAIS. In 18 patients these evaluations were performed at the time of their first visit and during a follow-up period ranging from 2 to 6 years. Anthropometric measurements were taken from all subjects: stature was measured with a stadiometer as the distance from the vertex to the floor by asking the subject to stand erect, barefoot with their shoulders touching the wall. Body mass index (BMI) was calculated as weight in kilograms divided by the square of height in metres $\left(\mathrm{kg} / \mathrm{m}^{2}\right)$. All patients underwent clinical, laboratory and radiologic assessment as per clinical practice. Bone parameters were assessed every 12-18 months and noted in patients' charts. At baseline and during follow-up, body composition and BMD were measured by dual X-ray absorptiometry using the Hologic 49159 densitometer and standard QDR body composition software (Model QDR4500W, Software Level 112, Hologic Spine, Hologic, Bedford, MA, USA) to evaluate body fat and lean mass. Spinal BMD was obtained between lumbar levels 1-4 (L1-L4) and total hip BMD at femoral neck, trochanteric and intertrochanteric regions. The results of BMD were provided in $\mathrm{g} / \mathrm{cm}^{2}$. The $T$ score indicates how much the value of BMD measured in a bone site differs from that of the reference sample, consisting of healthy subjects aged 25-30 years (the age at which peak bone mass is reached). The World Health Organization (WHO) criteria divides BMD values as follows: normal: BMD between +2.5 and -1.0 DS compared to the average peak bone mass value in a young adult (T score), osteopenia: BMD between -1 and -2.5 DS and osteoporosis: BMD value below -2.5 DS. The $\mathrm{Z}$ score indicates the number of standard deviations of values measured in bone sites and how they deviate from those measured in the healthy reference population, consisting of subjects of the same sex and age as CAIS patients being studied.

Laboratory test results recorded were oestradiol (E), luteinising hormone (LH), follicle-stimulating hormone (FSH), haematocrit (Ht), haemoglobin ( $\mathrm{Hb})$, fasting glucose, fasting insulin, total cholesterol (Tot Chol), high- and lowdensity lipoproteins (HDL and LDL), triglycerides (TG), aspartate and alanine aminotransferases (AST and ALT), prothrombin time (PT), activated partial thromboplastin 
time (aPTT), fibrinogen (factor I), osteocalcin (OC), parathyroid hormone (PTH), bone alkaline phosphatase (BAP) and 25-hydroxyvitamin (Vit D). Fasting insulin resistance (HOMA-IR) was calculated using the formula $\mathrm{HOMA}-\mathrm{IR}=($ fasting insulin in $\mu \mathrm{U} / \mathrm{mL} \times$ fasting glucose in $\mathrm{nmol} / \mathrm{L}) / 22.5$. Laboratory tests were performed by the same hospital laboratory. For the control group hormonal tests were performed in the follicular phase of the cycle (days 3-5). Progesterone measurement should have been performed in the luteal phase, but it was not available for the majority of controls and for this reason we excluded it from the analysis.

The present study was approved by the Medical Ethics Committee of S. Orsola-Malpighi University Hospital, Bologna, (137/2017/O/Oss) in accordance with the 1975 Helsinki Declaration, and all patients gave written informed consent.

\section{Statistical analysis}

All continuous data are expressed as mean and standard deviation and all categorical data are expressed by frequency rate and percentage. The Kolmogorov-Smirnov test was used to assess the normality of distributions. When data were normally distributed, parametric Student's $t$-test was used to assess differences between the two groups. Otherwise the Mann-Whitney test was used. Tests used are detailed in table legends. Bone and metabolic parameters and scores during follow-up were compared using oneway repeated-measures ANOVA. Pearson's nonparametric chi-squared test or Fisher's nonparametric chi-squared test was performed to investigate the relationships between categoric variables. To investigate factors influencing BMD multiple linear regression was used. $P<.05$ was considered significant. Statistical analysis was carried out by means of the Statistical Package for the Social Sciences (SPSS) software, version 23.0 (International Business Machines Corp., Armonk, NY, USA).

\section{Results}

\section{Demographic and clinical characteristics of women with CAIS and controls}

Thirty-six women with CAIS were potentially eligible and were screened. According to our exclusion criteria four women were not enrolled. The remaining 32 women with CAIS were enrolled and thus included in the data analysis. Mean age was $34.5 \pm 10.4$ years (range: 19-57 years) (Table 1). All patients had undergone gonadectomy at a mean age of $12.3 \pm 7.9$ years (range $0-24$ years). Mean HRT duration at the time of their first visit in our centre was $17.4 \pm 11.6$ years and all patients were using HT. The control group consisted of 32 healthy, age-matched women of similar BMI to the CAIS patients. In the control group, there were more current smokers than in the CAIS group. All participants in the study were Caucasian and born in Italy. Performed tests: when data were normally distributed, parametric Student's t-test was used to assess differences between the two groups. Otherwise the MannWhitney test was used (used only for BMI).

\section{Bone parameters}

Bone parameters in CAIS and age-matched healthy controls

At the time of their first visit to our centre, lumbar, femoral and total body BMD were significantly lower in the CAIS group when compared with the control group: $0.94 \pm 0.13$ vs $1.10 \pm 0.14, P<0.0001,0.88 \pm 0.14$ vs $1.01 \pm 0.11$, $P<0.0001$ and $1.01 \pm 0.13$ vs $1.15 \pm 0.09,<0.0001$, respectively (Table 2). Fat mass was not significantly different between the two groups (Table 2). Fifty-six point three percent (18/32) and 25\% (8/32) of CAIS patients presented lumbar osteopenia and osteoporosis respectively, while $53.1 \%(17 / 32)$ and $9.4 \% \quad(3 / 32)$ patients presented femoral osteopenia and osteoporosis. Prevalence of vertebral osteoporosis and osteopenia was significantly higher in the CAIS group (8/32 and 18/32 in CAIS vs $1 / 32$ and $8 / 32$ in controls, $P=0.038$, $O R=9.67$, 95\% CI: $1.13-82.83$ and $P=0.012, \mathrm{OR}=3.85,95 \% \mathrm{CI}: 1.34$ 11.16 , respectively). Prevalence of femoral osteopenia was significantly higher in the CAIS group (17/32 vs 4/32, $P=0.0012$, OR=7.93, 95\% CI: 2.26-27.9), while femoral osteoporosis was more prevalent in CAIS group even if the difference was not significant (4/32 in CAIS vs $0 / 32$ in controls, $P=0.12, \mathrm{OR}=10.3,95 \% \mathrm{CI}$ : $0.53-199)$. No osteoporotic fractures were detected in the CAIS and control patients during follow-up and in anamnesis.

\section{Analysis of factors potentially influencing $B M D$}

In CAIS patients we analysed factors potentially associated to BMD values at various bone sites. The results of the multivariate linear regression analysis are presented in Table 3. Only the total body BMD values were found to be positively associated to some variables.

Total body BMD values were positively associated to the duration and the route of oestrogen administration 
Table 1 Baseline anthropometric, clinical and hormonal status of CAIS patients at the time of their first visit in our centre and control women. Values are expressed as mean \pm S.D. unless otherwise noted.

\begin{tabular}{|c|c|c|}
\hline & CAIS $(n=32)$ & Controls $(n=32)$ \\
\hline Age (years) & $34.5 \pm 10.4$ & $34.5 \pm 10.4$ \\
\hline Body weight (kg) & $62.3 \pm 11.2$ & $61.9 \pm 8.7$ \\
\hline Height (cm) & $168.4 \pm 6.6$ & $165.8 \pm 6.2$ \\
\hline BMI $\left(\mathrm{kg} / \mathrm{m}^{2}\right)$ & $21.3 \pm 5.3$ & $23.3 \pm 3.7$ \\
\hline Age at gonadectomy (years) & $12.3 \pm 7.9$ & n.a. \\
\hline Time from gonadectomy to HT start (years) & $4.4 \pm 5.7$ & n.a. \\
\hline Age at HT start (years) & $17.5 \pm 5.7$ & n.a. \\
\hline HT duration (years) & $17.4 \pm 11.6$ & n.a. \\
\hline Smokers n (\%) & $4(12.5 \%)$ & $15(46.9 \%)^{*}$ \\
\hline $\mathrm{E} 2(\mathrm{pg} / \mathrm{mL})$ & $29.2 \pm 40.6$ & $120.8 \pm 79.9 *$ \\
\hline $\mathrm{FSH}(\mathrm{mUI} / \mathrm{mL})$ & $56.2 \pm 42.9$ & $5.6 \pm 3.8 *$ \\
\hline $\mathrm{LH}(\mathrm{mUI} / \mathrm{mL})$ & $30.1 \pm 19.3$ & $8.6 \pm 5.8 *$ \\
\hline Testosterone (ng/mL) & $0.20 \pm 0.13$ & $0.55 \pm 0.23$ \\
\hline Progesterone (ng/mL) & $0.52 \pm 0.28$ & n.a. \\
\hline
\end{tabular}

$* P<.05$.

BMI, body mass index; E2, estradiol; FSH, follicle-stimulating hormone; HT, hormonal therapy; LH, luteinising hormone.

and to serum estradiol levels. Transdermal administration of estrogens was associated with better total body BMD in comparison to oral administration.

\section{Bone parameters in CAIS women during follow-up of oestrogen therapy}

We were able to analyse 18 patients who presented at least three DXA scans during 6 years of follow-up (Table 4). Evaluations were grouped as follows: at first visit (T0), at years 1-3 (T1) and years 4-6 (T3). All patients reported continuous and correct use of their prescribed hormonal therapy. Eight patients were using transdermal estradiol $2 \mathrm{mg}$ (Sandrena transdermal gel) and ten oral estradiol valerate $2 \mathrm{mg}$ (Progynova oral pills). During follow-up lumbar BMD showed a significant increase $(P=0.0016)$, while femoral and total body BMD did not show any significant change $(P=0.917$ and $P=0.286)$ (Table 4). BMI and body composition did not show any significant change. Monitored bone turnover markers (OC, BAP, PTH did not show any significant change during the observation period. Vitamin D showed a significant increase during follow-up as patients diagnosed with hypovitaminosis D were supplemented as per current clinical practice. No osteoporotic fractures were detected in CAIS women during follow-up.

\section{Anthropometric parameters}

BMI at baseline was within the normal range and fat mass percentage was similar between the CAIS and control groups (Table 1). BMI and body composition did not show any significant change during follow-up (Table 4).

Table 2 Comparison of DXA parameters between CAIS patients and age-matched women. Values are expressed as mean \pm S.D. unless otherwise noted.

\begin{tabular}{|c|c|c|}
\hline & CAIS $(n=32)$ & Controls $(n=32)$ \\
\hline$\overline{\text { Lumbar BMD }\left(\mathrm{g} / \mathrm{cm}^{2}\right)}$ & $0.94 \pm 0.13$ & $1.10 \pm 0.14$ \\
\hline Lumbar Z score & $-1.60 \pm 0.92$ & $-0.66 \pm 0.96$ \\
\hline Lumbar T score & $-1.95 \pm 0.94$ & $-0.86 \pm 0.98$ \\
\hline Femoral BMD $\left(\mathrm{g} / \mathrm{cm}^{2}\right)$ & $0.88 \pm 0.14$ & $1.01 \pm 0.11$ \\
\hline Femoral Z score & $-1.17 \pm 1.00$ & $-0.01 \pm 0.67$ \\
\hline Femoral T score & $-1.30 \pm 1.20$ & $-0.003 \pm 0.78$ \\
\hline TB BMD (g/cm²) & $1.01 \pm 0.13$ & $1.15 \pm 0.09$ \\
\hline TB Z score & $-0.69 \pm 1.19$ & $0.91 \pm 0.74$ \\
\hline TB T score & $-0.84 \pm 1.39$ & $0.79 \pm 0.93$ \\
\hline Fat mass (\%) & $35.79 \pm 6.61$ & $35.3 \pm 6.68$ \\
\hline
\end{tabular}

\begin{tabular}{c}
\hline Difference between means \\
\hline$-0.1869 \pm 0.03502$ \\
$-0.9337 \pm 0.2634$ \\
$-1.059 \pm 0.3251$ \\
$-0.1653 \pm 0.03074$ \\
$-1.229 \pm 0.2362$ \\
$-1.369 \pm 0.2779$ \\
$-0.1541 \pm 0.02994$ \\
$1.600 \pm 0.2477$ \\
$1.639 \pm 0.2956$ \\
$-0.5000 \pm 1.664$
\end{tabular}

\begin{tabular}{c}
$\mathbf{9 5 \%} \mathbf{C l}$ \\
\hline-0.2570 to -0.1168 \\
-1.460 to -0.4069 \\
-1.712 to -0.4055 \\
-0.2268 to 0.1038 \\
-1.705 to -0.7536 \\
-1.929 to -0.8097 \\
-0.2142 to -0.09411 \\
1.105 to 2.095 \\
1.039 to 2.221 \\
-3.826 to 2.826 \\
\hline
\end{tabular}

\begin{tabular}{c}
\hline P value \\
\hline$<0.0001$ \\
0.0008 \\
0.002 \\
$<0.0001$ \\
$<0.0001$ \\
$<0.0001$ \\
$<0.0001$ \\
$<0.0001$ \\
$<0.0001$ \\
Ns $(0.76)$
\end{tabular}

Performed test: data were normally distributed and parametric Student's t-test was used to assess differences between the two groups. $\mathrm{BMI}$, body mass index; BMD, bone mineral density; TB, total body. 
Table 3 Linear regression analysis to identify factors associated to lumbar femoral and total body BMD at the time of the first visit.

\begin{tabular}{|c|c|}
\hline Dependent variable & Variables \\
\hline Lumbar BMD & $\begin{array}{l}\text { Age } \\
\text { BMI } \\
\text { Fat mass } \\
\text { Age at gonadectomy } \\
\text { Duration of therapy } \\
\text { Type of therapy (transdermal or oral) } \\
\text { FSH } \\
\text { LH } \\
\text { Estradiol }\end{array}$ \\
\hline Femoral BMD & $\begin{array}{l}\text { Age } \\
\text { BMI } \\
\text { Fat mass } \\
\text { Age at gonadectomy } \\
\text { Duration of therapy } \\
\text { Type of therapy (transdermal or oral) } \\
\text { FSH } \\
\text { LH } \\
\text { Estradiol }\end{array}$ \\
\hline Total body BMD & $\begin{array}{l}\text { Age } \\
\text { BMI } \\
\text { Fat mass } \\
\text { Age at gonadectomy } \\
\text { Duration of therapy } \\
\text { Type of therapy (transdermal or oral) } \\
\text { FSH } \\
\text { LH } \\
\text { Estradiol }\end{array}$ \\
\hline
\end{tabular}

\begin{tabular}{c}
\hline B coefficient \\
\hline 0.005 \\
0.004 \\
0.003 \\
-0.001 \\
0.007 \\
0.201 \\
0.001 \\
-0.005 \\
-0.0003 \\
-0.006 \\
0.033 \\
-0.016 \\
-0.003 \\
0.005 \\
-0.090 \\
-0.001 \\
-0.001 \\
-0.001 \\
\\
0.245 \\
0.004 \\
-0.004 \\
-0.023 \\
0.007 \\
-0.062 \\
-0.001 \\
-0.0003 \\
0.004 \\
\hline
\end{tabular}

\begin{tabular}{|c|c|}
\hline $95 \% \mathrm{Cl}$ & $P$ value \\
\hline-0.015 to 0.026 & 0.366 \\
\hline-0.081 to 0.089 & 0.844 \\
\hline-0.056 to 0.06 & 0.846 \\
\hline-0.023 to 0.021 & 0.910 \\
\hline-0.012 to 0.027 & 0.269 \\
\hline-0.361 to 0.763 & 0.264 \\
\hline-0.007 to 0.010 & 0.461 \\
\hline-0.026 to 0.016 & 0.427 \\
\hline-0.012 to 0.011 & 0.910 \\
\hline-0.030 to 0.018 & 0.381 \\
\hline-0.067 to 0.134 & 0.289 \\
\hline-0.085 to 0.054 & 0.433 \\
\hline-0.030 to 0.023 & 0.617 \\
\hline-0.018 to 0.029 & 0.422 \\
\hline-0.756 to 0.575 & 0.618 \\
\hline-0.012 to 0.009 & 0.621 \\
\hline-0.025 to 0.024 & 0.937 \\
\hline-0.014 to 0.013 & 0.900 \\
\hline 0.082 to 0.132 & 0.429 \\
\hline-0.004 to 0.012 & 0.146 \\
\hline-0.009 to 0.002 & 0.099 \\
\hline-0.137 to -0.091 & 0.474 \\
\hline 0.004 to 0.008 & 0.004 \\
\hline-0.115 to -0.009 & 0.037 \\
\hline-0.001 to 0.0002 & 0.098 \\
\hline-0.002 to 0.002 & 0.568 \\
\hline 0.003 to 0.005 & 0.004 \\
\hline
\end{tabular}

Performed test: multiple linear regression with Bonferroni correction.

$\mathrm{BMD}$, bone mineral density; BMI, body mass index; FSH, follicle-stimulating hormone $\mathrm{LH}$, luteinising hormone.

\section{Metabolic parameters}

Metabolic parameter changes are shown in Table 4. Total cholesterol, HDL and LDL cholesterol did not show significant variations throughout the study period. Triglycerides did not significantly change. Fasting insulin concentrations showed a progressive but not significant decrease from baseline $(P=0.07)$, while fasting glucose remained stable within the normal range. The HOMA index showed a slight but not significant decrease during observation.

\section{Discussion}

In this study we evaluated bone, body composition, anthropometric and metabolic parameters in women living with CAIS compared to age-matched female controls and after a maximum of 6 years of hormone intake compared to baseline. At baseline lumbar, femoral and total body BMD were lower in CAIS compared to the control group and also compared to normal values in young healthy female adults (T score) and in healthy female subjects of the same age ( $Z$ score). All 32 enrolled patients presented some impairment of bone health with osteopenia or osteoporosis, with major reductions of BMD at the lumbar level. The intake of hormone replacement therapy had improved BMD at lumbar spine and avoided further BMD decreases at femoral level where it was not sufficient to significantly increase bone mineral density after a maximum of 6 years of therapy. No significant changes of anthropometric, metabolic or biochemical parameters were detected throughout the 6 years of follow-up.

CAIS is a known risk factor for bone health. Numerous studies have shown reduced BMD in these patients compared to the normal ranges for both women and men (13). Low $\mathrm{BMD}$ has been reported both before and after gonadectomy probably due to the combination of oestrogen deficiency and bone resistance to androgen action (9, 14). After gonadectomy, hormone replacement is mandatory to avoid bone loss, but reduced BMD has also been demonstrated in patients reporting good compliance with the therapy 
Table 4 Anthropometric, bone and metabolic parameters in CAIS using estrogens during follow-up. Values are expressed as mean \pm s.D. unless otherwise noted.

\begin{tabular}{|c|c|c|}
\hline & TO $(n=18)$ & T1 $(y r 1-3)(n=18)$ \\
\hline Body weight & $60.7 \pm 9.0$ & $62.6 \pm 12.2$ \\
\hline $\mathrm{BMI}\left(\mathrm{kg} / \mathrm{m}^{2}\right)$ & $21.8 \pm 3.4$ & $22.4 \pm 4.3$ \\
\hline Lumbar BMD (g/cm²) & $0.95 \pm 0.09$ & $0.97 \pm 0.09$ \\
\hline Femoral BMD $\left(\mathrm{g} / \mathrm{cm}^{2}\right)$ & $0.85 \pm 0.16$ & $0.85 \pm 0.12$ \\
\hline TB BMD $\left(\mathrm{g} / \mathrm{cm}^{2}\right)$ & $1.03 \pm 0.14$ & $1.04 \pm 0.12$ \\
\hline Lean mass (kg) & $37.4 \pm 3.7$ & $39.1 \pm 5.1$ \\
\hline Fat mass (kg) & $21.6 \pm 5.2$ & $23.3 \pm 7.5$ \\
\hline Osteocalcin (ng/mL) & $29.4 \pm 24.0$ & $23.8 \pm 14.2$ \\
\hline PTH (pg/mL) & $42.2 \pm 19.1$ & $43.8 \pm 26.3$ \\
\hline Vit D (ng/mL) & $18.6 \pm 6.4$ & $28.0 \pm 16.2$ \\
\hline PBA (mcg/L) & $19.2 \pm 10.8$ & $13.4 \pm 4.7$ \\
\hline Glycaemia (mg/dL) & $84.1 \pm 5.5$ & $84.1 \pm 7.3$ \\
\hline Insulin (microUl/mL) & $9.6 \pm 5.2$ & $8.1 \pm 3.8$ \\
\hline HOMA-IR & $2.3 \pm 1.7$ & $1.6 \pm 0.8$ \\
\hline Tot Chol (mg/dL) & $186.4 \pm 21.9$ & $186.3 \pm 23.4$ \\
\hline $\mathrm{HDL}(\mathrm{mg} / \mathrm{dL})$ & $76.9 \pm 20.2$ & $77.8 \pm 17.9$ \\
\hline LDL (mg/dL) & $97.2 \pm 25.7$ & $99.4 \pm 27.7$ \\
\hline $\mathrm{TG}(\mathrm{mg} / \mathrm{dL})$ & $83.0 \pm 27.1$ & $78.2 \pm 28.8$ \\
\hline
\end{tabular}

\begin{tabular}{c}
\hline T2 $(\mathrm{yr} 4-6)(n=18)$ \\
\hline $62.6 \pm 11.9$ \\
$22.4 \pm 4.1$ \\
$0.99 \pm 0.08$ \\
$0.86 \pm 0.11$ \\
$1.05 \pm 0.10$ \\
$40.7 \pm 4.1$ \\
$23.1 \pm 6.9$ \\
$20.8 \pm 9.6$ \\
$41.8 \pm 21.3$ \\
$37.8 \pm 12.9$ \\
$13.6 \pm 4.9$ \\
$85.4 \pm 12.1$ \\
$4.8 \pm 1.4$ \\
$1.6 \pm 0.8$ \\
$180.6 \pm 21.2$ \\
$75.1 \pm 15.8$ \\
$102.9 \pm 34.6$ \\
$78.5 \pm 23.5$ \\
\end{tabular}

\begin{tabular}{c}
\hline DF \\
\hline 2 \\
2 \\
2 \\
2 \\
2 \\
2 \\
2 \\
2 \\
2 \\
2 \\
2 \\
2 \\
2 \\
2 \\
2 \\
2 \\
2 \\
2 \\
\hline
\end{tabular}

\begin{tabular}{c}
\hline MS \\
\hline 22.01 \\
2.561 \\
0.009 \\
0.0001 \\
0.003 \\
3.522 \\
0.314 \\
137.9 \\
24.64 \\
590.4 \\
74.8 \\
2.795 \\
32.93 \\
2.859 \\
136.1 \\
28.67 \\
481.6 \\
157.8 \\
\hline
\end{tabular}

\begin{tabular}{cccc}
\hline \multicolumn{1}{c}{$\mathbf{F}$} & & $\boldsymbol{P}$ value \\
\cline { 1 - 1 } 2.593 & & 0.115 \\
2.555 & & 0.117 \\
5.367 & & 0.016 \\
0.035 & & 0.917 \\
1.263 & & 0.286 \\
1.378 & & 0.274 \\
0.068 & & 0.905 \\
1.096 & & 0.336 \\
0.162 & & 0.796 \\
9.485 & & 0.008 \\
2.843 & & 0.157 \\
0.059 & & 0.886 \\
3.539 & & 0.070 \\
2.549 & & 0.134 \\
0.902 & & 0.389 \\
0.359 & & 0.661 \\
1.368 & & 0.267 \\
0.347 & & 0.682 \\
\hline
\end{tabular}

Performed test: one-way repeated-measures ANOVA.

BMD, bone mineral density; BMI, body mass index; HDL, high-density lipoproteins cholesterol; HOMA-IR, Fasting Insulin Resistance Index; LDL, lowdensity lipoproteins cholesterol; PBA, bone alkaline phosphatase; PTH, parathyroid hormone; TB, total body; Tot Chol, total cholesterol; TG, triglycerides; Vit. D, 25-hydroxyvitamin.

$(7,9,13)$. The mechanisms regulating BMD in CAIS have not yet been completely identified and the absence of androgen function on the bone may be a relevant contributor to BMD impairment, particularly in the lumbar region. In all previous studies, the most important deficit of bone mineral density is recorded at the level of the lumbar spine, where the trabecular bone is prevalent $(7,9,15)$. The trabecular bone is a known major target of androgens, as already demonstrated in the murine model (16), while estrogens offer more protection to the cortical bone. As further proof that androgenic activity is fundamental for bone trophism, Marcus et al. (2000) evaluated 28 patients including 22 CAIS and 6 partial AIS (PAIS) (11). Blood estrogen levels were similar in the two groups of patients; however, BMD was reduced in the CAIS group, whereas in the PAIS group it was normal, suggesting that even partial androgenic action may protect bone mass (11).

Studies of CAIS are scant, mostly retrospective and with a short follow-up during hormonal treatment (6, $7,8,9,10,11)$. Our study is the first to analyse bone parameters prospectively in gonadectomised CAIS using appropriate HT for a maximum of 6 years. In our study lumbar BMD showed a significant increase. BMD remained stable at femoral site and in the total body evaluation in most of our CAIS patients during the 6 years of follow-up; however, it did not increase or reach the normal range in spite of the good compliance to HT.
In our cohort, the multivariate linear regression analysis showed that total body BMD values were positively associated to the duration and route of hormonal treatment and to plasmatic estradiol levels.

In our cohort, total body BMD values at baseline were significantly higher in patients using transdermal estradiol when compared to oral estradiol users. These results are consistent with previous studies in women with premature ovarian insufficiency $(17,18,19)$. The mechanism of this effect may be explained by the different effect on IGF-I secretion, a bone-trophic hormone which is downregulated by oral administration only (20).

Serum testosterone and progesterone levels were not related to BMD in our study. Progesterone values were within the male range. Progesterone may play a role in bone health increasing mature osteoblast and production of collagen bone matrix both in men and women $(21,22)$. Previous studies in different populations showed that progesterone plus oestrogens therapy was associated with greater lumbar BMD when compared to oestrogen therapy alone $(23,24)$. Whether CAIS patients could benefit by the addition of a progestin to the estrogen remains unexplored.

FSH values were negatively associated with total body BMD even if the association was not statistically significant. However, it should be considered that in the animal model a shorter FSH-receptor isoform was found to be able to increase osteoclast formation, function and 
survival and FSH was associated to TNF alpha production by bone marrow $(25,26,27)$. A polyclonal antibody against a short, receptor-binding epitope of FSH $\beta$ was found to rescue bone loss post-ovariectomy in mice (28).

Consistent with previous reports (29), we did not find any correlation between age at gonadectomy and lumbar and femoral $\operatorname{BMD}(6,8,15)$.

Throughout the follow-up period, our patients showed a slight but not significant decrease in insulin values with a slight but not significant decrease in insulin resistance. These results may be explained by the potential effect of estrogens on glucose metabolism (30) but also by the slight increase in lean mass.

Some limitations of this study should be acknowledged. This condition is quite rare and this may have led to a statistical type II error, leading to our inability to detect further subtle changes. Moreover, considering the number of subjects, the interpretation of some statistically significant associations should be made with caution. Although the cohort group attended a single centre, the group was heterogeneous. In our study we analysed not only lumbar spine and femoral BMD but also total body BMD. Although the role of total body $\mathrm{T}$ score in fracture prediction is still debated, the concordance between lumbar and hip $\mathrm{T}$ score and those of total body was variable $(31,32,33)$. The number of smokers was different between the CAIS and control groups (higher in control group) and may represent a limit of this comparison because of the potential negative effects of smoking on bone health. Another limitation of our study was the unavailability of bone mineral apparent density (BMAD) measurement at DXA which was reported in two other studies in this population $(7,11)$. BMAD $(\mathrm{g} /$ $\mathrm{cm}^{3}$ ) is believed to better reflect bone density and avoid errors due to bone size particularly in tall subjects (34). However it should be noted that in our cohort CAIS height was $168.4 \pm 6.6 \mathrm{~cm}$ (range $159-175 \mathrm{~cm}$ ), lower than in the cohort reported by Marcus et al. $(174 \pm 7.3 \mathrm{~cm})$. For this reason we believe that the impact of height can be considered minimal in our analysis.

In conclusion, this is the first study to present a prospective follow-up of bone and metabolic parameters in gonadectomised CAIS patients using estrogens for a maximum of six years. We confirm previous studies suggesting that BMD is impaired in gonadectomised women living with CAIS compared to $46, \mathrm{XX}$ women, with lumbar spine BMD more affected than that of the hip. Oestrogen therapy in our patients was able to significantly increase BMD at the lumbar spine during a maximum of 6 years of follow-up. Femoral and total body BMD were maintained in most subjects but did not improve nor normalise during follow-up. Plasma estradiol levels and duration of hormonal treatment were positively associated to BMD values. Transdermal administration of estrogens seemed to be associated with better total body BMD values in comparison to oral administration.

Future studies are needed to respond to the many questions that remain open on the effects of oestrogen treatment on the bones of CAIS subjects among which the evaluation of whether longer treatment may lead to better BMD in these women, whether higher doses of estrogens may be more effective or whether the addition of testosterone or progesterone may further improve BMD.

\section{Declaration of interest}

The authors declare that there is no conflict of interest that could be perceived as prejudicing the impartiality of this study.

\section{Funding}

This research did not receive any specific grant from funding agencies in the public, commercial, or not-for-profit sectors.

\section{Acknowledgements}

The authors thank Julie Norbury for English copy editing and Professor Ada Dormi for statistical analysis supervision.

\section{References}

1 Berglund A, Johannsen TH, Stochholm K, Viuff MH, Fedder J, Main KM \& Gravholt $\mathrm{CH}$. Incidence, prevalence, diagnostic delay, and clinical presentation of female $46, \mathrm{XY}$ disorders of sex development. Journal of Clinical Endocrinology and Metabolism 2016 101 4532-4540. (https://doi.org/10.1210/jc.2016-2248)

2 Döhnert U, Wünsch L \& Hiort O. Gonadectomy in complete androgen insensitivity syndrome: why and when? Sexual Development 201711 171-174. (https://doi.org/10.1159/000478082)

3 Tack LJW, Maris E, Looijenga LHJ, Hannema SE, Audi L, Köhler B, Holterhus PM, Riedl S, Wisniewski A, Flück CE et al. Management of gonads in adults with androgen insensitivity: an international survey. Hormone Research in Paediatrics 201890 236-246. (https://doi. org/10.1159/000493645)

4 Cools M, Drop SLS, Wolffenbuttel KP, Oosterhuis JW \& Looijenga LHJ. Germ cell tumors in the intersex gonad: old paths, new directions, moving frontiers. Endocrine Reviews 200627 468-484. (https://doi.org/10.1210/er.2006-0005)

5 Huang H, Wang C \& Tian Q. Gonadal tumour risk in 292 phenotypic female patients with disorders of sex development containing Y chromosome or Y-derived sequence. Clinical Endocrinology $2017 \mathbf{8 6}$ 621-627. (https://doi.org/10.1111/cen.13255)

6 Bertelloni S, Baroncelli GI, Federico G, Cappa M, Lala R \& Saggese G. Altered bone mineral density in patients with complete androgen insensitivity syndrome. Hormone Research 199850 309-314. (https:// doi.org/10.1159/000023296)

7 Danilovic DLS, Correa PHS, Costa EMF, Melo KFS, Mendonca BB $\&$ Arnhold IJP. Height and bone mineral density in androgen insensitivity syndrome with mutations in the androgen receptor gene. Osteoporosis International 200718 369-374. (https://doi. org/10.1007/s00198-006-0243-6) 
8 Sobel V, Schwartz B, Zhu YS, Cordero JJ \& Imperato-McGinley J. Bone mineral density in the complete androgen insensitivity and 5alphareductase-2 deficiency syndromes. Journal of Clinical Endocrinology and Metabolism 200691 3017-3023. (https://doi.org/10.1210/jc.2005-2809)

9 Han TS, Goswami D, Trikudanathan S, Creighton SM \& Conway GS. Comparison of bone mineral density and body proportions between women with complete androgen insensitivity syndrome and women with gonadal dysgenesis. European Journal of Endocrinology 2008159 179-185. (https://doi.org/10.1530/EJE-08-0166)

10 Soule SG, Conway G, Prelevic GM, Prentice M, Ginsburg J \& Jacobs HS. Osteopenia as a feature of the androgen insensitivity syndrome. Clinical Endocrinology 199543 671-675. (https://doi. org/10.1111/j.1365-2265.1995.tb00533.x)

11 Marcus R, Leary D, Schneider DL, Shane E, Favus M \& Quigley CA. The contribution of testosterone to skeletal development and maintenance: lessons from the androgen insensitivity syndrome. Journal of Clinical Endocrinology and Metabolism 200085 1032-1037. (https://doi.org/10.1210/jcem.85.3.6428)

12 Taes Y, Lapauw B, Vandewalle S, Zmierczak H, Goemaere S, Vanderschueren D, Kaufman JM \& T'Sjoen G. Estrogen-specific action on bone geometry and volumetric bone density: longitudinal observations in an adult with complete androgen insensitivity. Bone 200945 392-397. (https://doi.org/10.1016/j.bone.2009.04.198)

13 Bertelloni S, Meriggiola MC, Dati E, Balsamo A \& Baroncelli GI. Bone mineral density in women living with complete androgen insensitivity syndrome and intact testes or removed gonads. Sexual Development 201711 182-189. (https://doi.org/10.1159/000477599)

14 Soule SG, Conway G, Prelevic GM, Prentice M, Ginsburg J \& Jacobs HS. Osteopenia as a feature of the androgen insensitivity syndrome. Clinical Endocrinology 199543 671-675. (https://doi. org/10.1111/j.1365-2265.1995.tb00533.x)

15 Bertelloni S, Dati E, Baroncelli GI \& Hiort O. Hormonal management of complete androgen insensitivity syndrome from adolescence onward. Hormone Research in Paediatrics 201176 428-433. (https:// doi.org/10.1159/000334162)

16 Chang C, Yeh S, Lee SO \& Chang TM. Androgen receptor (AR) pathophysiological roles in androgen related diseases in skin, metabolism syndrome, bone/muscle and neuron/immune systems: lessons learned from mice lacking AR in specific cells. Nuclear Receptor Signaling 201311 e001. (https://doi.org/10.1621/nrs.11001)

17 Nabhan ZM, Dimeglio LA, Qi R, Perkins SM \& Eugster EA. Conjugated oral versus transdermal estrogen replacement in girls with Turner syndrome: a pilot comparative study. Journal of Clinical Endocrinology and Metabolism 200994 2009-2014. (https://doi. org/10.1210/jc.2008-2123)

18 Guttmann H, Weiner Z, Nikolski E, Ish-Shalom S, Itskovitz-Eldor J, Aviram M, Reisner S \& Hochberg Z. Choosing an oestrogen replacement therapy in young adult women with Turner syndrome. Clinical Endocrinology 200154 159-164. (https://doi.org/10.1046/ j.1365-2265.2001.01181.x)

19 Cartwright B, Robinson J, Seed PT, Fogelman I \& Rymer J. Hormone replacement therapy versus the combined oral contraceptive pill in premature ovarian failure: a randomized controlled trial of the effects on bone mineral density. Journal of Clinical Endocrinology and Metabolism 2016101 3497-3505. (https://doi.org/10.1210/jc.2015-4063)

20 Kam GY, Leung KC, Baxter RC \& Ho KK. Estrogens exert route- and dose-dependent effects on insulin-like growth factor (IGF)-binding protein-3 and the acid-labile subunit of the IGF ternary complex. Journal of Clinical Endocrinology and Metabolism 200085 1918-1922. (https://doi.org/10.1210/jcem.85.5.6527)
21 Prior JC. Progesterone as a bone-trophic hormone. Endocrine Reviews 199011 386-398. (https://doi.org/10.1210/edrv-11-2-386)

22 Schmidmayr M, Magdolen U, Tübel J, Kiechle M, Burgkart R \& Seifert-Klauss V. Progesteron verstärkt die Differenzierung primärer humaner Osteoblasten in Langzeit-Kulturen. Geburtshilfe und Frauenheilkunde 200868 722-728. (https://doi. org/10.1055/s-2008-1038711)

23 Prior JC, Seifert-Klauss VR, Giustini D, Adachi JD, Kalyan S \& Goshtasebi A. Estrogen-progestin therapy causes a greater increase in spinal bone mineral density than estrogen therapy - a systematic review and meta-analysis of controlled trials with direct randomization. Journal of Musculoskeletal and Neuronal Interactions 201717 146-154.

24 Wierckx K, Gooren L \& T'Sjoen G. Clinical review: breast development in trans women receiving cross-sex hormones. Journal of Sexual Medicine 201411 1240-1247. (https://doi.org/10.1111/jsm.12487)

25 Iqbal J, Sun L, Kumar TR, Blair HC \& Zaidi M. Follicle-stimulating hormone stimulates TNF production from immune cells to enhance osteoblast and osteoclast formation. PNAS 2006103 14925-14930. (https://doi.org/10.1073/pnas.0606805103)

26 Zaidi M, Lizneva D, Kim SM, Sun L, Iqbal J, New MI, Rosen CJ, Yuen T. FSH, bone mass, body fat, and biological aging. Endocrinology 2018159 3503-3514. (https://doi.org/10.1210/en.2018-00601)

27 Sun L, Peng Y, Sharrow AC, Iqbal J, Zhang Z, Papachristou DJ, Zaidi S, Zhu LL, Yaroslavskiy BB, Zhou H et al. FSH directly regulates bone mass. Cell 2006125 247-260. (https://doi.org/10.1016/j. cell.2006.01.051)

28 Ji Y, Liu P, Yuen T, Haider S, He J, Romero R, Chen H, Bloch M, Kim SM, Lizneva D et al. Epitope-specific monoclonal antibodies to FSH $\beta$ increase bone mass. PNAS 2018115 2192-2197. (https://doi. org/10.1073/pnas.1718144115)

29 King TFJ, Wat WZM, Creighton SM \& Conway GS. Bone mineral density in complete androgen insensitivity syndrome and the timing of gonadectomy. Clinical Endocrinology 201787 136-140. (https:// doi.org/10.1111/cen.13368)

30 Yan H, Yang W, Zhou F, Li X, Pan Q, Shen Z, Han G, NewellFugate A, Tian Y, Majeti R et al. Estrogen improves insulin sensitivity and suppresses gluconeogenesis via the transcription factor FoxO1. Diabetes 201968 291-304. (https://doi.org/10.2337/ db18-0638)

31 Rosenthall L, Falutz J \& Guaraldi G. The relationships between total body, lumbar spine and femoral neck bone mineral density T-scores for diagnosis of low bone mass in HIV-infected patients. Journal of Clinical Nutrition and Metabolism 2018 [cited 2019 May 5] 2018 (available at: (https://www.scitechnol.com/abstract/the-relationshipsbetween-total-body-lumbar-spine-and-femoral-neck-bone-mineraldensity-tscores-for-diagnosis-of-low-bone-mass-in-7148.html).

32 Graat-Verboom L, Spruit MA, van den Borne BEEM, Smeenk FWJM $\&$ Wouters EFM. Whole-body versus local DXA-scan for the diagnosis of osteoporosis in COPD patients. Journal of Osteoporosis [Internet] 2010 [cited 2019 May 5] 2010 1-6. (available at: (https:// www.hindawi.com/journals/jos/2010/640878/). (https://doi. org/10.4061/2010/640878)

33 Rajaei A, Dehghan P, Ariannia S, Ahmadzadeh A, Shakiba M \& Sheibani K. Correlating whole-body bone mineral densitometry measurements to those from local anatomical sites. Iranian Journal of Radiology 201613 e25609.

34 Carter DR, Bouxsein ML \& Marcus R. New approaches for interpreting projected bone densitometry data. Journal of Bone and Mineral Research 19927 137-145. (https://doi.org/10.1002/ jbmr.5650070204)

Received 22 May 2019

Revised version received 29 July 2019

Accepted 14 August 2019 